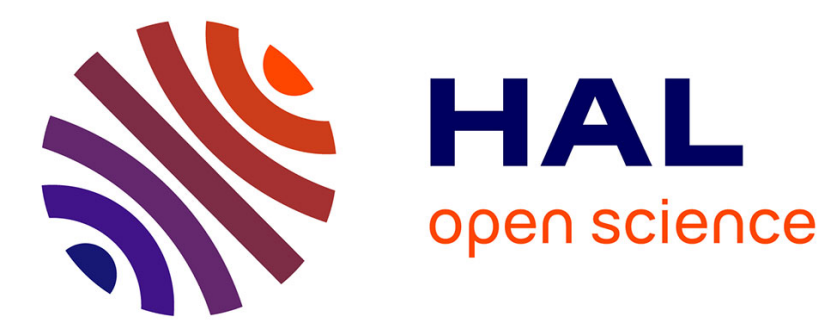

\title{
Abutment rotational freedom on five implant systems with different internal connections
}

\author{
Yvan Bédouin, Etienne Lefrançois, Jean-Pierre Salomon, Pascal Auroy
}

\section{To cite this version:}

Yvan Bédouin, Etienne Lefrançois, Jean-Pierre Salomon, Pascal Auroy. Abutment rotational freedom on five implant systems with different internal connections. Journal of Prosthetic Dentistry, 2023, 129

(3), pp.433-439. 10.1016/j.prosdent.2021.04.027 . hal-03333661

\section{HAL Id: hal-03333661 \\ https://hal.science/hal-03333661}

Submitted on 15 Sep 2021

HAL is a multi-disciplinary open access archive for the deposit and dissemination of scientific research documents, whether they are published or not. The documents may come from teaching and research institutions in France or abroad, or from public or private research centers.
L'archive ouverte pluridisciplinaire HAL, est destinée au dépôt et à la diffusion de documents scientifiques de niveau recherche, publiés ou non, émanant des établissements d'enseignement et de recherche français ou étrangers, des laboratoires publics ou privés.

\section{다)(1) $(5$}

Distributed under a Creative Commons Attribution - NonCommerciall 4.0 International 
JPD-20-1245

RESEARCH AND EDUCATION

Abutment rotational freedom on five implant systems with different internal connections

\section{Yvan Bédouin ${ }^{1}$, Etienne Lefrançois ${ }^{2}$, Jean-Pierre Salomon ${ }^{3}$, Pascal Auroy ${ }^{4}$}

1 Associate Professor, CHU Rennes, Univ Rennes, INSA Rennes, CNRS, ISCR (Rennes Institute of Chemical Sciences), Rennes, France. Electronic address: yvan.bedouin@univrennes1.fr.

2 Assistant Professor, CHU Rennes, Univ Rennes, INSA Rennes, CNRS, ISCR (Rennes Institute of Chemical Sciences), Rennes, France.

3 Associate Professor, CHU Nancy, Université de Lorraine, Nancy, France; UMR 7361

CNRS Université de Haute Alsace, Mulhouse, France; Clinical Associate Professor, Department of Restorative Dentistry, OHSU, Portland, Ore.

4 Professor, Department of Prosthodontics, University of Auvergne Clermont, Clinical Research Laboratory in Prosthetic Dentistry, CHU Clermont-Ferrand, Dental Services, Clermont-Ferrand, France.

\section{ABSTRACT}

Statement of problem. Information regarding the rotational freedom of internal connection implants is sparse.

Purpose. The purpose of this in vitro study was to compare the rotational freedom of different internal conical and internal nonconical connections. 
Material and methods. Thirty implants, 30 straight manufactured standard abutments, and 30 standard abutment screws were obtained for each of the 5 implant systems tested. Three implant systems had indexed internal conical connections with different antirotational geometries: hexagon (Naturall+; Euroteknika), cam-groove (ID CAM M; Implants Diffusion International), and octagon (Bone Level; Institut Straumann AG). Two implant systems had internal nonconical connections with hexagonal antirotational geometry (Tapered Screw-Vent; Zimmer-Biomet Dental and Seven; MIS). The implants were mounted in a steel plate, and a metal reference arm was attached to the abutment. Before tightening the standard abutment screw, a modified torque wrench was used to rotate the abutment clockwise until reaching the clockwise rotational endpoint. This modified torque wrench was connected to the abutment's outer surface. It allowed free access to the standard abutment screw for a second torque wrench, specific to each implant system. The modified torque wrench applied a controlled torque of 5 Ncm, which held the abutment at the clockwise rotational endpoint. The standard abutment screw was then tightened to the manufacturer's specified torque value with the second torque wrench. Angle value corresponding to the clockwise endpoint was measured microscopically between a fixed reference point on the steel plate and the reference arm. The abutment was then unscrewed and removed. The same procedure was carried out to rotate the abutment counterclockwise and measure the angle value corresponding to the counterclockwise rotational endpoint. The rotational freedom was finally determined from the differences in the angles between the clockwise and counterclockwise rotational endpoints. Rotational freedom angle values were summarized as descriptive statistics (means, standard deviations). The normality test (Kolmogorov-Smirnov) was applied, and the Kruskal-Wallis test was performed. The 
Wilcoxon signed-rank test was used to isolate the implant system differences from each other $(\alpha=.05)$.

Results. The lowest mean rotational freedom angles were obtained for Bone Level (conical connection, 0.17 degrees) and Tapered Screw-Vent (nonconical connection, 0.05 degrees). These systems were followed in increasing order by ID CAM M (conical connection, 0.50 degrees), Seven (nonconical connection, 1.98 degrees), and Naturall+ (conical connection, 2.49 degrees). Compared with each other, all implant systems had significant statistical differences in rotational freedom angles $(P<.05)$.

Conclusions. Significant differences were found among the 5 implant systems. The lowest mean rotational freedom angles were obtained both with a conical connection (Bone Level) and a nonconical connection (Tapered Screw-Vent).

\section{CLINICAL IMPLICATIONS}

Positional stability of the implant-abutment connection is essential since multiple repositioning of the implant components is necessary during the clinical and technical steps of the fabrication and fitting of the superstructure. For single-tooth implant-supported prostheses, priority should be given to implant systems with limited rotational freedom to minimize rotational misfit and to reduce the risks of mechanical or technical screw-related complications.

\section{INTRODUCTION}

Despite dental implant studies that report long-term survival rates well above 90\%, biological and mechanical complications can affect up to $33 \%$ of all implant-supported prostheses. ${ }^{1-3}$ These complications have a multifactorial etiology, and the clinical incidence varies among

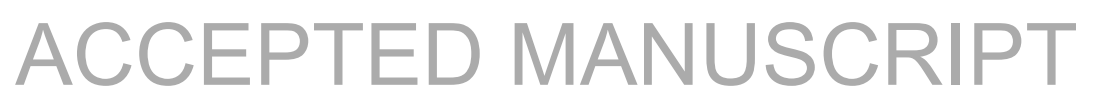


different implant systems. ${ }^{4}$ Positional stability of the implant-abutment connection is essential since multiple repositionings of the implant components are necessary during the fabrication and fitting of the superstructure by the dental laboratory technician and the dentist. ${ }^{5} \mathrm{~A}$ poor fit at the implant-abutment connection has been reported to result in microgaps, causing higher micromovements of the structural parts on mastication or occlusal prematurity from incomplete seating. ${ }^{6}$ Vertical and horizontal misfits can lead to the concentration of the loading stresses in both the implant and the bone. How the degree of misfit affects the clinical outcomes of screwretained implant-supported fixed dentures is unclear, but the aim for clinicians is to minimize misfit as much as possible. $^{7}$

Before tightening the abutment screw, an abutment can be partially rotated back and forth in horizontal micromovements within the dimensions of the interfacial void between the antirotational elements. ${ }^{8}$ This phenomenon corresponds to rotational freedom, leading to horizontal misfit, and has mainly been studied for external connections. ${ }^{9-19}$ A linear correlation has been reported between the rotational freedom and screw loosening with such connections. Long-term clinical data and in vitro mechanical evaluations have demonstrated that, although external hexagon implant-abutment connections are more susceptible to abutment screw loosening and fracture than implants with internal connections, the same problems can occur with any screw-retained abutment and prosthesis. ${ }^{8,20-26}$

Rotational displacement of the abutment influences the fit of the prosthetic superstructure compared with the neighboring teeth, antagonist dentition, and periodontium and may adversely affect prosthesis insertion if the abutments are angled. ${ }^{27}$ Errors in the rotational positioning of components can result in the need to adjust proximal contacts chairside. It is, therefore, essential to ensure the position stability of the implant-abutment connection. More

\section{ACCEPTED MANUSCRIPT}


particularly, for single-tooth implant-supported prostheses, the rotational freedom must be as low as possible.

Indexed internal connections are available with both slip-fit and friction-fit joint designs. ${ }^{28,29}$ For slip-fit interfaces (nonconical connections), the lateral surfaces of the antirotational elements must be allowed to slip past one another. For friction-fit connections (conical connections), there is no interfacial space between the implant and abutment parts. Internal connections help reduce the incidence of screw loosening, improve load distribution, enhance sealing capabilities at the implant-abutment interface, and improve the implant's ability to withstand large axial loads in comparison with implants with external hexagon connections. ${ }^{30-32}$ Finite element analysis results have revealed a proper gradual stress distribution for internal connections, resulting in adjacent bone being less affected by high loads when compared with external connections. ${ }^{6}$ Internal connections also increase contact pressure and frictional resistance, theoretically enhancing the mechanical stability of the implant-abutment connection. ${ }^{33-36}$

However, studies evaluating the rotational freedom of implants with internal connections are sparse, and there are even fewer evaluations of implants with internal conical connections. ${ }^{14,17}$ The effect of the design on abutment rotational freedom has not been adequately reported in the dental literature. ${ }^{37-40}$ Moreover, experimental rotational freedom deviates greatly from the theoretical value because of manufacturing tolerance. ${ }^{5,41}$ For these reasons, experimental studies on rotational freedom by following the clinical procedures recommended by each implant system are necessary to compare implant designs and systems.

The present investigation aimed to measure and compare the rotational freedom of 5 implant systems with different designs of indexed internal connections. The research hypothesis

\section{ACCEPTED MANUSCRIPT}


was that each implant system's specific internal connection would differ in terms of rotational freedom angle value.

\section{MATERIAL AND METHODS}

A total of 150 dental implants with indexed internal connections and 150 straight manufactured standard abutments for cemented restorations were obtained from 5 manufacturers (30 standard abutments, 30 standard abutment screws, and 30 implants for each implant system). The 3 implant systems consisted of indexed internal conical connections with different antirotational geometries: hexagon (Naturall+; Euroteknika), cam-groove (ID CAM M; Implants Diffusion International), and octagon (Bone Level; Institut Straumann AG). Two implant systems consisted of internal nonconical connections with the same hexagonal antirotational geometry (Tapered Screw-Vent; Zimmer-Biomet Dental and Seven; MIS). The dimensions and characteristics of each implant system are summarized in Table 1.

For each implant system, thirty Ø5-mm holes were drilled $20 \mathrm{~mm}$ apart in a $150 \times 180 \times 25-\mathrm{mm}$ steel plate. At a distance of $10 \mathrm{~mm}$ to the right of each hole, an additional Ø3mm hole was drilled in the steel plate to serve as a fixed point of reference (R) (Figs. 1, 2).

Each implant was positioned in the center of the Ø5-mm hole with the coronal aspect of the implant flush with the upper surface of the steel plate. Epoxy resin (SR 1700; Sicomin) was injected into the hole to cement the implant in place.

After the epoxy resin had polymerized, a metal reference arm was fixed on the abutment, and the abutment was placed on the implant. The standard abutment screw was tightened to $1 \mathrm{Ncm}$, as described by Garine et al, ${ }^{15}$ with a torque wrench (TWR; ZimmerBiomet Dental) with the specific implant system drivers (Table 1). This standardized initial

\section{ACCEPTED MANUSCRIPT}


tightening of the screw was adequate to hold the components together while offering minimal resistance to abutment rotation.

A torque wrench (TWR; Zimmer-Biomet Dental) was modified to be connected to the abutment's outer surface with a ratchet wheel (reference number 1000222; Josef Ganter), adapted to the specific shape of each abutment. This modified torque wrench allowed free access to the standard abutment screw for the specific implant system torque wrench (Fig. 1). The modified torque wrench was used to rotate the abutment clockwise until it reached the clockwise rotational endpoint. A torque of $5 \mathrm{Ncm}$ was applied, which held the abutment at the clockwise rotational endpoint $\left(E_{1}\right)$ in a controlled way (Fig. 2). This corresponded to the maximum measured torque found when an abutment was manually set on an implant previously fixed on a digital torque tester (unpublished results). While holding the abutment in place with this controlled torque value of $5 \mathrm{Ncm}$, the standard abutment's screw was tightened to the torque indicated by each implant manufacturer with the specific implant system torque wrench (Table 1). All torque applications were performed with torque wrenches calibrated on a digital torque tester (Series TT01; Mark-10 Corp).

Rotational freedom angle values were measured by using a contactless measurement microscope (Inexiv VMA-2520; Nikon Metrology Inc) with a computer-controlled, imageanalysis software program (Inexiv Auto Measure; Nikon Metrology Inc). This equipment allowed precise, three-dimensional (3D) measurements of $1 \mu \mathrm{m}$ for distances and 0.001 degrees for angles. All measurements were made by the same operator (Y.B.) in a closed microscope room maintained at a constant temperature and humidity. The first measurement was conducted to determine the angle between the fixed point of reference $(\mathrm{R})$ on the steel plate, the axis of the abutment (A), and the clockwise rotational endpoint ( $\left.E_{1}\right)\left(\angle R A E_{1}\right)$ (Fig. 2).

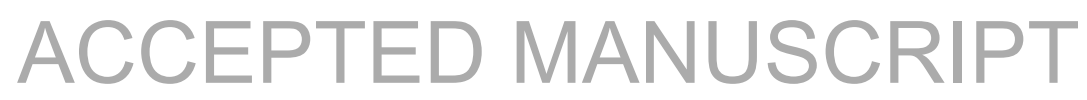


For the second measurement, the standard abutment screw was unthreaded, and the abutment was removed from the implant. The reference arm remained attached to the abutment. The abutment with the reference arm was then placed back on the implant at the same initial position in the implant-abutment connection. The standard abutment screw was tightened to 1 Ncm. The same procedure as previously described was carried out to rotate the abutment counterclockwise and measure the angle value corresponding to the counterclockwise rotational endpoint $\left(E_{2}\right)$.

The angle was measured between the fixed point of reference (R), the axis of the abutment (A), and the counterclockwise rotational endpoint $\left(E_{2}\right)\left(\angle R A E_{2}\right)$. The rotational freedom (arc of motion) value $\left(\angle \mathrm{E}_{1} \mathrm{AE}_{2}\right.$ ) was calculated by subtracting the 2 measurement values: $\mathrm{RAE}_{1}-\mathrm{RAE}_{2}=\mathrm{E}_{1} \mathrm{AE}_{2}$. Rotational freedom angle values $\left(\angle \mathrm{E}_{1} \mathrm{AE}_{2}\right)$ were obtained for all 30 paired implant-abutment assemblies in each implant system (Fig. 2).

A power analysis was carried out to determine the sample size after a pilot study, indicating that a specimen size of $n=30$ was adequate for a power of $80 \%$ at a significance threshold of $\alpha=.05$ (epiR package, v0.9-96; The University of Melbourne). For each implant system, rotational freedom angles were summarized as descriptive statistics (means, standard deviations). All statistical analyses were performed with a statistical software program (IBM SPSS Statistics, v26; IBM Corp). The Kolmogorov-Smirnov normality test was applied to all implant systems, and the Kruskal-Wallis test was performed. The Wilcoxon signed-rank test was used to isolate the implant system differences from each other $(\alpha=.05)$.

\section{RESULTS}


Mean rotational freedom angle values ranged from 0.05 degrees (Tapered Screw-Vent) to 2.49 degrees (Naturall+). The mean rotational angle values were 0.17 degrees for Bone Level, 0.50 degrees for ID CAM M, and 1.98 degrees for the Seven implant system (Fig. 3). The Kolmogorov-Smirnov normality test indicated that the data distribution was not normal $(P<.001)$ and that there were significant differences in mean rank rotational freedom angle values by implant systems ( $P<.001)$, which made it possible to classify them (Table 2$)$. Hence, the least rotational freedom angle values were obtained by using the Tapered Screw-Vent implant system followed in increasing order by Bone Level, ID CAM M, Seven, and Naturall+. The Wilcoxon signed-rank test showed that rotational freedom angle values for all implant systems were significantly different from each other $(P<.05)$.

\section{DISCUSSION}

Considering the rotational freedom angle values between the abutments and the implants, all of the implant systems tested were significantly different from each other; therefore, the study hypothesis was not rejected. Very low rotational freedoms were obtained both with Bone Level (conical connection) and Tapered Screw Vent (nonconical connection). Unexpectedly, the contemporary conical connections (Naturall+, ID CAM M, Bone Level) were not as effective as a nonconical connection (Tapered Screw-Vent) in reducing rotational freedom. These results were consistent with those of another study where the magnitude of rotational freedom between impression coping and implant replica pairs was significantly higher for conical connections than for butt joint connections. ${ }^{4}$

All the internal connections tested in this study, regardless of the design, were more effective than the old external hexagon connection in reducing rotational freedom values.

\section{ACCEPTED MANUSCRIPT}


Indeed, among external hexagon connections, rotational values ranged from 1.01 to 14.87 degrees, with an average of around 4 degrees. ${ }^{9,11-18}$ In vitro testing has shown that abutment rotation of less than 2 degrees resists a mean of 6.7 million loading cycles before loosening ${ }^{9}$ and also high resistance to screw loosening. Only the Naturall+ implant system exceeded this value while remaining well below the 5 degrees described by $\operatorname{Binon}^{9}$ as significantly more prone to screw loosening. Rotational freedom was below or equal to 0.5 degrees for the ID CAM M, Bone Level, and Tapered Screw-Vent systems, which should ensure mechanical performance. For the Seven implant system, the mean rotational freedom was slightly below 2 degrees, but the standard deviation was relatively high (0.83 degrees), indicating greater variability of the position stability. When using an implant system with greater rotational freedom, an individual abutment alignment coping should be used to place the definitive abutment in order to prevent any risk of rotation during clinical procedures. ${ }^{42}$

Differences have been reported between the implant-abutment coupling of internal connecting systems. ${ }^{24}$ Since this study selected implants with similar diameters (4.0 to $4.5 \mathrm{~mm}$ ), this variable had little effect on the results. Such differences are presumably from various designs and geometries of the connections, as well as from the machining tolerances applied by each manufacturer. When a screw-retained abutment is assembled on a dental implant, an interfacial void between their mated antirotational geometries helps ensure that the components can easily fit together to prevent abutment rotation. ${ }^{8}$ The space allowed for this is specified in the manufacturing of machined components and is known as machining tolerance ${ }^{41}$ Hence, the range of acceptable sizes (tolerances) used by a manufacturer can result in a variety of interfacial voids between the mated components. ${ }^{8}$ This is probably why the rotational freedom was different between the Tapered Screw-Vent and Seven implant systems, although they were

\section{ACCEPTED MANUSCRIPT}


almost identical in terms of dimension, chemical composition, tightening torque, and connection design.

For all connections, the geometric design, distance of the antirotational element relative to the axis of the implant, and the presence, angulation and extent of tapered surfaces can also influence the rotational freedom of the abutment. For example, the polygonal profile of some internal antirotational features has been reported to provide an increase in rotational freedom compared with that of a cam-groove connection. ${ }^{43}$ In the present investigation, although the cam-groove connection of ID CAM M showed relatively low rotational freedom (0.5 degrees), this system had higher rotational freedom than the octagon connection of Bone Level and the hexagon connection of Tapered Screw-Vent. This increase was probably because the cams of the ID CAM M abutments engage the grooves of the implant near its center or rotational axis. On the contrary, the Tapered Screw-Vent implant system showed the lowest rotational freedom, probably because the internal hexagon connection initially engages the implant near its circumference, distant from its rotational axis. ${ }^{5,43}$ Secondarily, in this system, the abutment hexagon presents a specific conicity of 1 degree. This design forms a frictional contact with the parallel internal walls of the implant's internal hexagon, which probably reduces the clearance and limits the influence of machining tolerance.

In an earlier study of Bone Level components, Semper-Hogg et $\mathrm{al}^{5}$ reported a mean rotational freedom value of 1.09 degrees, which was much higher than the 0.17 -degree mean rotational freedom value obtained in the present study. Differences in testing methods can explain this disparity: Semper-Hogg et $\mathrm{al}^{5}$ conducted 20 successive tests, while the present investigation only performed a single test on each implant-abutment sample. By performing multiple tests on each component assembly, the rotational freedom test could induce wear of

\section{ACCEPTED MANUSCRIPT}


the abutment-implant connection. ${ }^{22}$

The importance of using system-specific tightening torque has been reported to help prevent loosening from embedment relaxation of the screw threads after initial tightening. ${ }^{25}$ Regardless of the design of the connections, numerous studies have reported that the rotational freedom depended on whether the implant-abutment complexes were tightened with a torque wrench or manually. ${ }^{5,9,14,17,19,43}$ Repeated tightening of abutment screws has also been reported to reduce preload, which is associated with screw loosening and abutment rotation. ${ }^{44}$ Hence, the present study used the torque levels recommended by each manufacturer to evaluate and compare the 5 implant systems.

For indexed conical connections, the geometry of the connections tends to reduce rotational misfit when the screw is tightened to the system-specific tightening torque. This reduction is because the taper of the connection centers the abutment in the implant, while the full engagement of the antirotational elements brings the abutment to a middle rotational position and the friction of the screw head on the abutment encourages it to rotate clockwise, reducing the extent of counter-clockwise movement. ${ }^{17,26}$ This phenomenon is probably why most studies using 3-dimensional finite element analysis reported very low rotational abutment movements or microgap enlargement under vertical and oblique occlusal loading with conical connection systems. ${ }^{33-36}$

In the present study, a 1-Ncm torque was applied for the initial pretightening of the standard abutment screw according to Garine et al. ${ }^{15}$ Moreover, before and during the tightening of the standard abutment screw with the specific implant system torque wrench, a 5Ncm torque was applied to the abutment's outer surface with a modified torque wrench. This corresponded to the maximum measured torque when an abutment was manually set on an

\section{ACCEPTED MANUSCRIPT}


implant. Hence, this protocol allowed the torque for the abutment rotation to be standardized while closely approximating the clinical conditions of the oral placement of an abutment on an implant. However, the comparison of rotational freedom with previous studies is limited because of the variety of protocols and assessment methods. Moreover, other materials used in clinical conditions like analogs and impression transfer copings must be tested. Vertical misfit could also be assessed. Hence, in addition to implants and abutments, analogs and impression transfer copings need to be tested simultaneously in future studies, as internal connection designs and implant systems continue to evolve.

\section{CONCLUSIONS}

Based on the findings of this in vitro study, the following conclusions were drawn:

1. All the indexed internal connections tested in this study showed rotational freedom angle values below 2.5 degrees.

2. Very low rotational freedoms (below 0.2 degrees) were obtained both with a conical connection (Bone Level; Institut Straumann AG) and an internal hexagon connection (Tapered Screw-Vent; Zimmer-Biomet Dental). However, significant disparities in the rotational freedom were found between the 5 implant systems tested.

3. Rotational freedom angle values were significantly different between implant systems with similar connection designs (Tapered Screw-Vent; Zimmer-Biomet Dental and Seven; MIS). Hence, similar connection designs do not systematically lead to similar rotational freedom.

\section{ACCEPTED MANUSCRIPT}




\section{REFERENCES}

1. Pjetursson B, Asgeirsson A, Zwahlen M, Sailer I. Improvements in implant dentistry over the last decade: comparison of survival and complication rates in older and newer publications. Int J Oral Maxillofac Implants 2014;29:308-24.

2. Pjetursson BE, Thoma D, Jung R, Zwahlen M, Zembic A. A systematic review of the survival and complication rates of implant-supported fixed dental prostheses (FDPs) after a mean observation period of at least 5 years. Clin Oral Implants Res 2012;23:22-38.

3. Vandeweghe S, Hawker P, De Bruyn H. An up to 12-year retrospective follow-up on immediately loaded, surface-modified implants in the edentulous mandible. Clin Implant Dent Relat Res 2016;18:323-31.

4. Nicoll RJ, Sun A, Haney S, Turkyilmaz I. Precision of fit between implant impression coping and implant replica pairs for three implant systems. J Prosthet Dent 2013;109:37-43.

5. Semper-Hogg W, Kraft S, Stiller S, Mehrhof J, Nelson K. Analytical and experimental position stability of the abutment in different dental implant systems with a conical implantabutment connection. Clin Oral Investig 2013;17:1017-23.

6. Apaza-Bedoya K, Tarce M, Benfatti CAM, Henriques B, Mathew MT, Teughels W, et al. Synergistic interactions between corrosion and wear at titanium-based dental implant connections: A scoping review. J Periodontal Res 2017;52:946-54.

7. Katsoulis J, Takeichi T, Sol Gaviria A, Peter L, Katsoulis K. Misfit of implant prostheses and its impact on clinical outcomes. Definition, assessment and a systematic review of the literature. Eur J Oral Implantol. 2017;10:121-38.

8. Vogel RE, Davliakos JP. Spline implant prospective multicenter study: interim report on prosthetic screw stability in partially edentulous patients. J Esthet Restor Dent 2002;14:225-37.

\section{ACCEPTED MANUSCRIPT}


9. Binon PP. The effect of implant/abutment hexagonal misfit on screw joint stability. Int J Prosthodont 1996;9:149-60.

10. Khraisat A, Abu-Hammad O, Al-Kayed AM, Dar-Odeh N. Stability of the implant/abutment joint in a single-tooth external-hexagon implant system: clinical and mechanical review. Clin Implant Dent Relat Res 2004;6:222-9.

11. Binon PP. Evaluation of machining accuracy and consistency of selected implants, standard abutments, and laboratory analogs. Int J Prosthodont 1995;8:162-78.

12. Binon PP. Evaluation of three slip fit hexagonal implants. Implant Dent 1996;5:235-48.

13. Davi LR, Golin AL, Bernardes SR, Araujo CA, Neves FD. In vitro integrity of implant external hexagon after application of surgical placement torque simulating implant locking. Braz Oral Res 2008;22:125-31.

14. de Barros Carrilho GP, Dias RP, Elias CN. Comparison of external and internal hex implants' rotational freedom: a pilot study. Int J Prosthodont 2005;18:165-6.

15. Garine WN, Funkenbusch PD, Ercoli C, Wodenscheck J, Murphy WC. Measurement of the rotational misfit and implant-abutment gap of all-ceramic abutments. Int J Oral Maxillofac Implants 2007;22:928-38.

16. Kano SC, Binon PP, Bonfante G, Curtis DA. The effect of casting procedures on rotational misfit in castable abutments. Int J Oral Maxillofac Implants 2007;22:575-9.

17. Vigolo P, Fonzi F, Majzoub Z, Cordioli G. An in vitro evaluation of titanium, zirconia, and alumina procera abutments with hexagonal connection. Int J Oral Maxillofac Implants 2006;21:575-80. 
18. Vigolo P, Fonzi F, Majzoub Z, Cordioli G. Evaluation of gold-machined UCLA-type abutments and CAD/CAM titanium abutments with hexagonal external connection and with internal connection. Int J Oral Maxillofac Implants 2008;23:247-52.

19. Binon PP, McHugh MJ. The effect of eliminating implant/abutment rotational misfit on screw joint stability. Int J Prosthodont 1996;9:511-9.

20. Feitosa PCP, de Lima APB, Silva-Concilio LR, Brandt WC, Claro Neves AC. Stability of external and internal implant connections after a fatigue test. Eur J Dent 2013;7:267-71. 21. Cha HS, Kim YS, Jeon JH, Lee JH. Cumulative survival rate and complication rates of single-tooth implant; focused on the coronal fracture of fixture in the internal connection implant. J Oral Rehabil 2013;40:595-602.

22. Chae S-W, Kim Y-S, Lee Y-M, Kim W-K, Lee Y-K, Kim S-H. Complication incidence of two implant systems up to six years: a comparison between internal and external connection implants. J Periodontal Implant Sci 2015;45:23-9.

23. Lee JH, Kim DG, Park CJ, Cho LR. Axial displacements in external and internal implantabutment connection. Clin Oral Implants Res 2014;25:83-9.

24. Gracis S, Michalakis K, Vigolo P, Vult von Steyern P, Zwahlen M, Sailer I. Internal vs. external connections for abutments/reconstructions: a systematic review. Clin Oral Implants Res 2012;23:202-16.

25. Jorneus L, Jemt T, Carlsson L. Loads and designs of screw joints for single crowns supported by osseointegrated implants. Int J Oral Maxillofac Implants 1992;7:353-9.

26. Lang LA, Wang RF, May KB. The influence of abutment screw tightening on screw joint configuration. J Prosthet Dent 2002;87:74-9. 
27. Dailey B, Jordan L, Blind O, Tavernier B. Axial displacement of abutments into implants and implant replicas, with the tapered cone-screw internal connection, as a function of tightening torque. Int J Oral Maxillofac Implants 2009;24:251-6.

28. Niznick G. The implant abutment connection: the key to prosthetic success. Compendium 1991;12:932, 934-8.

29. Niznick GA. The Core-Vent implant system. J Oral Implantol 1982;10:379-18.

30. Almeida EO, Freitas AC, Jr., Bonfante EA, Marotta L, Silva NR, Coelho PG. Mechanical testing of implant-supported anterior crowns with different implant/abutment connections. Int J Oral Maxillofac Implants 2013;28:103-8.

31. Balik A, Karatas MO, Keskin H. Effects of different abutment connection designs on the stress distribution around five different implants: a 3-dimensional finite element analysis. J Oral Implantol 2012;38:491-6.

32. Jimbo R, Halldin A, Janda M, Wennerberg A, Vandeweghe S. Vertical fracture and marginal bone loss of internal-connection implants: a finite element analysis. Int J Oral Maxillofac Implants 2013;28:171-6.

33. Hyun DG, Kwon HB, Lim YJ, Koak JY, Kim MJ. The influence of a positioning hex on abutment rotation in tapered internal implants: A 3D finite element model study. Int J Oral Maxillofac Implants 2020;35:281-8.

34. Kitagawa T, Tanimoto Y, Odaki M, Nemoto K, Aida M. Influence of implant/abutment joint designs on abutment screw loosening in a dental implant system. J Biomed Mater Res B Appl Biomater 2005;75:457-63.

35. Pessoa RS, Muraru L, Junior EM, Vaz LG, Sloten JV, Duyck J, et al. Influence of implant connection type on the biomechanical environment of immediately placed implants - CT-based

\section{ACCEPTED MANUSCRIPT}


nonlinear, three-dimensional finite element analysis. Clin Implant Dent Relat Res 2010;12:21934.

36. Yamanishi Y, Yamaguchi S, Imazato S, Nakano T, Yatani H. Influences of implant neck design and implant-abutment joint type on peri-implant bone stress and abutment micromovement: three-dimensional finite element analysis. Dent Mater 2012;28:1126-33. 37. Coppede AR, Faria AC, de Mattos Mda G, Rodrigues RC, Shibli JA, Ribeiro RF. Mechanical comparison of experimental conical-head abutment screws with conventional flat-head abutment screws for external-hex and internal tri-channel implant connections: an in vitro evaluation of loosening torque. Int J Oral Maxillofac Implants 2013;28:321-9.

38. Delben JA, Barao VA, Dos Santos PH, Assuncao WG. Influence of abutment type and esthetic veneering on preload maintenance of abutment screw of implant-supported crowns. J Prosthodont 2014;23:134-9.

39. Gumus HO, Zortuk M, Albayrak H, Dincel M, Kocaagaoglu HH, Kilinc HI. Effect of fluid contamination on reverse torque values in bone-level implants. Implant Dent 2014;23:582-7. 40. Yao KT, Kao HC, Cheng CK, Fang HW, Huang CH, Hsu ML. The potential risk of conical implant-abutment connections: the antirotational ability of Cowell implant system. Clin Implant Dent Relat Res 2015;17:1208-16.

41. Ma T, Nicholls JI, Rubenstein JE. Tolerance measurements of various implant components. Int J Oral Maxillofac Implants 1997;12:371-5.

42. Semper W, Kraft S, Mehrhof J, Nelson K. Impact of abutment rotation and angulation on marginal fit: theoretical considerations. Int J Oral Maxillofac Implants 2010;25:752-8.

43. Semper W, Kraft S, Kruger T, Nelson K. Theoretical optimum of implant positional index design. J Dent Res 2009;88:731-5.

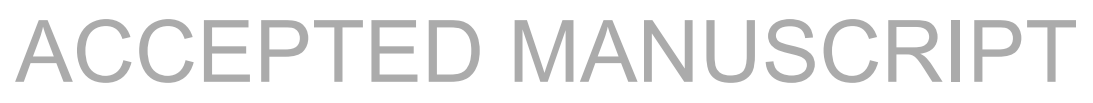


44. Byrne D, Jacobs S, O'Connell B, Houston F, Claffey N. Preloads generated with repeated tightening in three types of screws used in dental implant assemblies. J Prosthodont 2006;15:164-71. 


\section{TABLES}

Table 1. Specifications of implant components used for each implant system and systemspecific tightening torque values. Naturall+, ID CAM M and Bone Level implant systems had indexed internal conical connections. Tapered Screw-Vent and Seven implant systems had internal hexagon connections. Deg, degrees; GH, gingival height; Ti Cp: Titanium commercially pure.

\begin{tabular}{|c|c|c|c|c|c|c|c|c|c|c|}
\hline \multirow[b]{2}{*}{ System } & \multicolumn{3}{|c|}{ Implant } & \multicolumn{3}{|c|}{$\begin{array}{c}\text { Straight manufactured } \\
\text { standard abutment }\end{array}$} & \multicolumn{3}{|c|}{ Internal connection } & \multirow{2}{*}{\begin{tabular}{|c|}
$\begin{array}{c}\text { Torque } \\
\text { wrench }\end{array}$ \\
$\begin{array}{c}\text { Reference } \\
\text { number }\end{array}$ \\
\end{tabular}} \\
\hline & $\begin{array}{l}\text { Name and } \\
\text { Dimensions } \\
\varnothing \times \text { length } \\
(\mathrm{mm})\end{array}$ & $\begin{array}{l}\text { Reference } \\
\text { number }\end{array}$ & $\begin{array}{c}\text { Chemical } \\
\text { composition }\end{array}$ & $\begin{array}{c}\text { Dimensions } \\
\varnothing \times \mathrm{GH} \\
(\mathrm{mm})\end{array}$ & $\begin{array}{l}\text { Reference } \\
\text { number }\end{array}$ & $\begin{array}{c}\text { Chemical } \\
\text { composition }\end{array}$ & $\begin{array}{l}\text { Cone } \\
\text { angle } \\
\text { (Deg) }\end{array}$ & $\begin{array}{c}\text { Geometric } \\
\text { design }\end{array}$ & \begin{tabular}{|c|} 
System- \\
specific \\
tightening \\
torque \\
(Ncm)
\end{tabular} & \\
\hline $\begin{array}{c}\text { ETK } \\
\text { Euroteknika }\end{array}$ & $\begin{array}{c}\text { Naturall+ } \\
4.0 \times 14\end{array}$ & $\begin{array}{c}\text { NICP } 40 \\
140\end{array}$ & $\begin{array}{l}\text { Ti-6Al-4V } \\
\text { Grade } 5\end{array}$ & $4.5 \times 11.5$ & $\begin{array}{c}\text { NPS PD } \\
3646\end{array}$ & $\begin{array}{c}\text { Ti-6Al-4V } \\
\text { Grade } 5\end{array}$ & 11 & Hexagon & 25 & CCC35 \\
\hline \begin{tabular}{|c} 
IDI \\
Implants \\
Diffusion \\
International
\end{tabular} & $\begin{array}{c}\text { ID CAM M } \\
4.2 \times 15\end{array}$ & $\begin{array}{c}\text { IDCM } \\
1542\end{array}$ & $\begin{array}{l}\text { Ti-6Al-4V } \\
\text { Grade } 5\end{array}$ & $5.4 \times 9$ & 420001 & $\begin{array}{c}\text { Ti-6Al-4V } \\
\text { Grade } 5\end{array}$ & 2.5 & $\begin{array}{l}\text { Cam- } \\
\text { groove }\end{array}$ & 25 & 415 \\
\hline $\begin{array}{c}\text { Institut } \\
\text { Straumann } \\
\text { AG }\end{array}$ & $\begin{array}{c}\text { Bone Level } \\
4.1 \times 14\end{array}$ & 021.4414 & $\begin{array}{c}\text { Ti Cp } \\
\text { Grade } 4\end{array}$ & $5 \times 6.5$ & 022.4325 & $\begin{array}{c}\text { Ti Cp } \\
\text { Grade } 4\end{array}$ & 8 & Octagon & 35 & $\begin{array}{l}046.119 \\
046.049\end{array}$ \\
\hline $\begin{array}{c}\text { Zimmer- } \\
\text { Biomet } \\
\text { Dental }\end{array}$ & $\begin{array}{c}\text { Tapered } \\
\text { Screw-Vent } \\
4.5 \times 13\end{array}$ & TSVWB13 & $\begin{array}{l}\text { Ti-6Al-4V } \\
\text { Grade } 5\end{array}$ & $5.5 \times 10.5$ & HLA4/5 & $\begin{array}{l}\text { Ti-6Al-4V } \\
\text { Grade } 5\end{array}$ & - & Hexagon & 30 & TWR \\
\hline MIS & $\begin{array}{c}\text { Seven } \\
4.2 \times 13\end{array}$ & $\begin{array}{l}\text { MF7- } \\
13420\end{array}$ & $\begin{array}{c}\text { Ti-6Al-4V } \\
\text { Grade } 5\end{array}$ & $5.6 \times 11$ & MD-P0030 & $\begin{array}{c}\text { Ti-6Al-4V } \\
\text { Grade } 5\end{array}$ & - & Hexagon & 30 & MT-RI040 \\
\hline
\end{tabular}


Table 2. Mean and Standard Deviation (SD) angle values (degrees) of rotational freedom of straight manufactured standard abutments for each implant system.

\begin{tabular}{|c|c|c|c|c|c|}
\hline Implant system & Naturall+ & ID CAM M & Bone Level & $\begin{array}{c}\text { Tapered } \\
\text { Screw-Vent }\end{array}$ & Seven \\
\hline $\begin{array}{c}\text { Internal } \\
\text { connection } \\
\text { design }\end{array}$ & $\begin{array}{c}\text { Conical, } \\
\text { Hexagon }\end{array}$ & $\begin{array}{c}\text { Conical, } \\
\text { Cam-groove }\end{array}$ & $\begin{array}{c}\text { Conical, } \\
\text { Octagon }\end{array}$ & $\begin{array}{c}\text { Nonconical, } \\
\text { hexagon }\end{array}$ & $\begin{array}{c}\text { Nonconical, } \\
\text { hexagon }\end{array}$ \\
\hline $\begin{array}{c}\text { Mean } \\
\text { (degrees) }\end{array}$ & 2.49 & 0.50 & 0.17 & 0.05 & 1.98 \\
\hline $\begin{array}{c}\text { SD } \\
\text { (degrees) }\end{array}$ & 0.31 & 0.31 & 0.12 & 0.03 & 0.83 \\
\hline $\begin{array}{c}\text { Mean rank } \\
\text { (Kruskal- } \\
\text { Wallis test) }\end{array}$ & 125.15 & 70.10 & 46.98 & 21.75 & 113.52 \\
\hline
\end{tabular}




\section{FIGURES}

Figure 1. Experimental design: (1) implant; (2) straight manufactured standard abutment; (3) epoxy resin; (4) steel plate; (5) metal reference arm fixed on standard abutment. (a) rotational endpoint marker in metal reference arm and (b) fixed reference hole on steel plate; (6) modified torque wrench connected to abutment's outer surface with ratchet wheel adapted to each abutment's specific shape; (7) implant system screwdriver; (8) implant system torque wrench. Modified torque wrench (6) used to rotate standard abutment (2) clockwise until it reaches clockwise rotational endpoint. It allowed free access to standard abutment screw for second torque wrench (8), specific for each implant system. Modified torque wrench (6) applied controlled torque of $5 \mathrm{Ncm}$, which held abutment at clockwise rotational endpoint. Standard abutment screw then tightened to manufacturer's specified torque value with second torque wrench (8). Same procedure carried out to rotate abutment counterclockwise until it reached counterclockwise rotational endpoint.

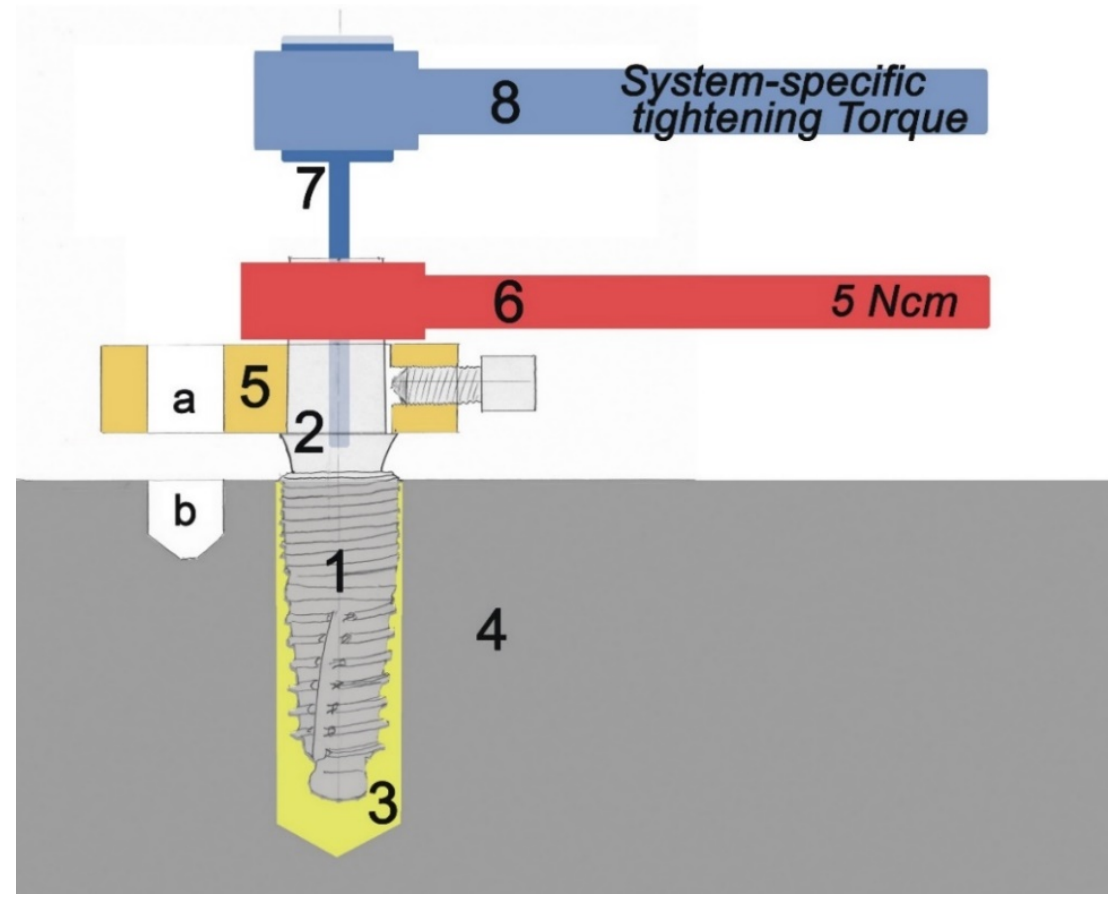


Figure 2. A, For each implant system, 30 straight manufactured standard abutments with attached metal reference arms positioned on implants previously fixed in steel plate to measure rotational freedom angle values by using contactless measurement microscope (Inexiv VMA2520; Nikon Metrology Inc). B, Set screw (top right) used to attach metal reference arm to abutment. Reference hole (R), axis of abutment (A), clockwise rotational endpoint $\left(\mathrm{E}_{1}\right)$ and counterclockwise rotational endpoint $\left(E_{2}\right)$ used to measure rotational freedom angle value by subtracting arc of motion of angle $\mathrm{RAE}_{1}$ from angle $\mathrm{RAE}_{2}\left(\mathrm{RAE}_{1}-\mathrm{RAE}_{2}=\mathrm{E}_{1} \mathrm{AE}_{2}=\right.$ rotational freedom angle value).

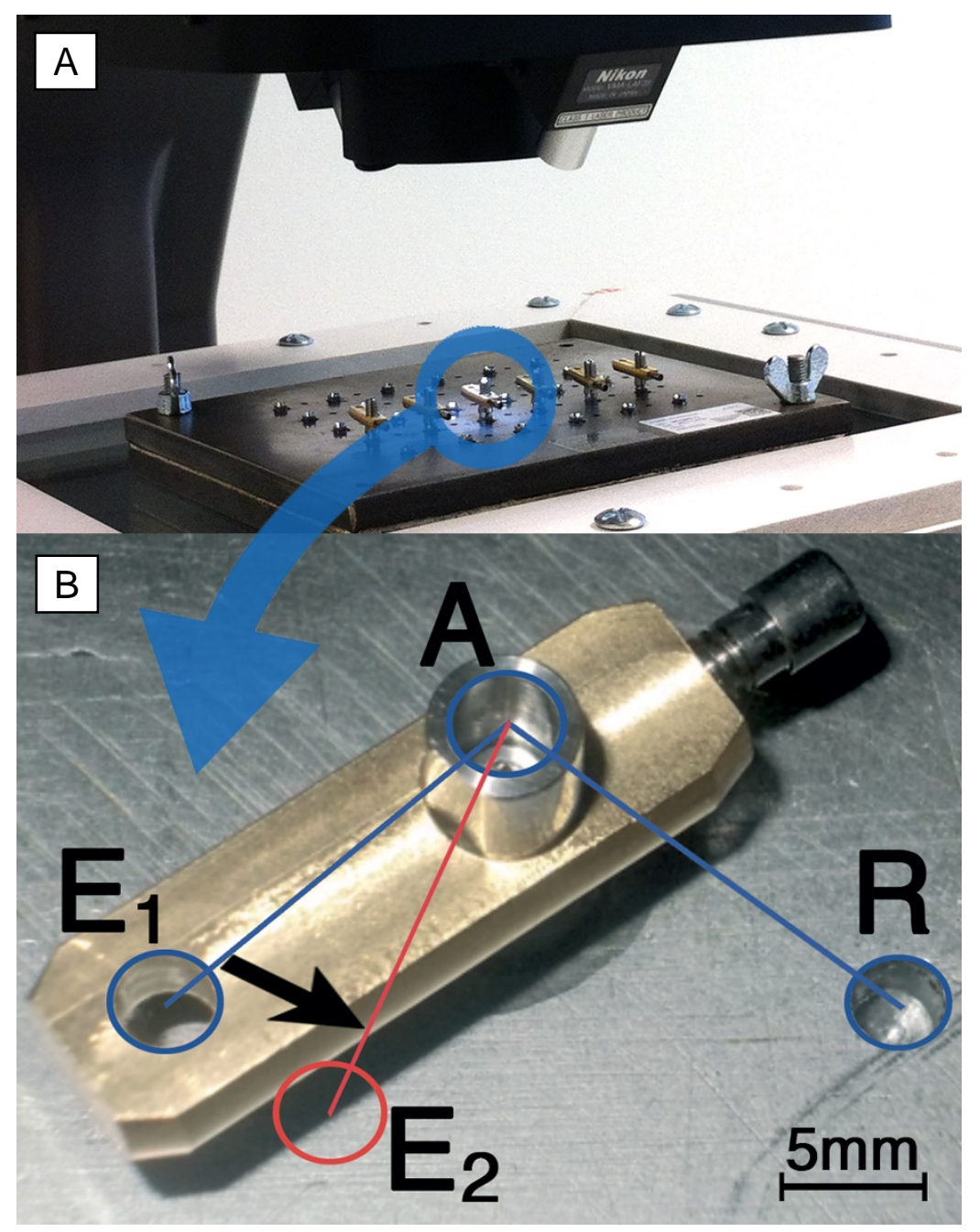


Figure 3. Mean rotational freedom angle values (degrees) of straight manufactured standard abutments for each implant system.

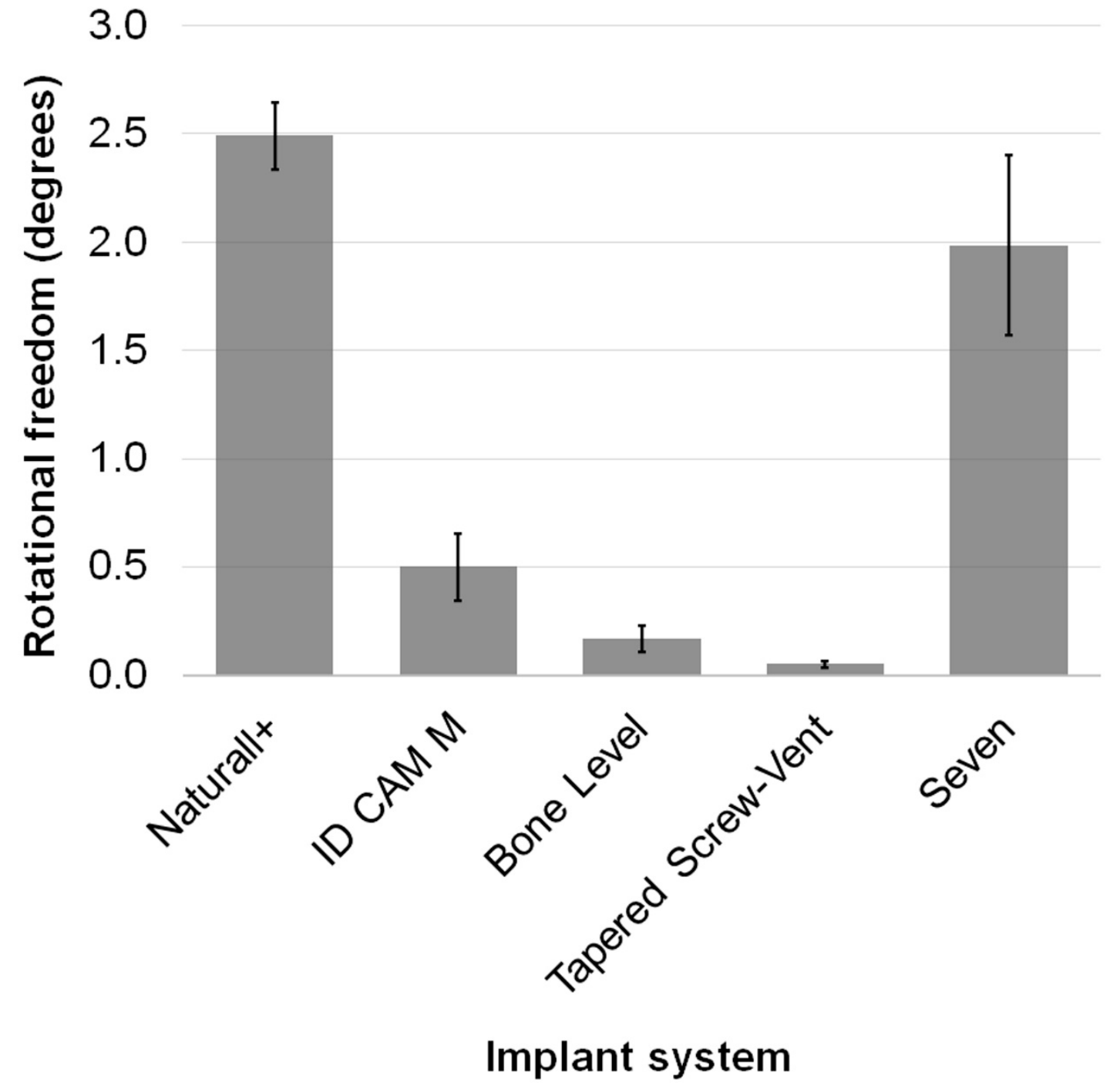

